\title{
Gold nanoparticles induce nuclear damage in breast cancer cells, which is further amplified by hyperthermia
}

\author{
Mohamed Kodiha $\cdot$ Eliza Hutter $\cdot$ Sebastien Boridy \\ Michal Juhas $\cdot$ Dusica Maysinger $\cdot$ Ursula Stochaj
}

Received: 6 May 2013 / Revised: 28 February 2014 / Accepted: 31 March 2014 / Published online: 17 April 2014

(C) Springer Basel 2014

\begin{abstract}
Gold nanoparticles have emerged as promising tools for cancer research and therapy, where they can promote thermal killing. The molecular mechanisms underlying these events are not fully understood. The geometry and size of gold nanoparticles can determine the severity of cellular damage. Therefore, small and big gold nanospheres as well as gold nanoflowers were evaluated side-by-side. To obtain quantitative data at the subcellular and molecular level, we assessed how gold nanoparticles, either alone or in combination with mild hyperthermia, altered the physiology of cultured human breast cancer cells. Our analyses focused on the nucleus, because this organelle is essential for cell survival. We showed that all the examined gold nanoparticles associated with nuclei. However, their biological effects were quantitatively different. Thus, depending on the shape and size, gold nanoparticles changed multiple nuclear parameters. They redistributed stress-sensitive regulators of nuclear biology, altered the nuclear morphology, reorganized nuclear laminae and envelopes, and inhibited nucleolar functions. In particular, gold nanoparticles reduced the de novo biosynthesis of RNA in nucleoli, the subnuclear compartments that produce ribosomes. While small gold nanospheres and nanoflowers, but not big gold
\end{abstract}

Electronic supplementary material The online version of this article (doi:10.1007/s00018-014-1622-3) contains supplementary material, which is available to authorized users.

M. Kodiha $\cdot$ U. Stochaj $(\triangle)$

Department of Physiology, McGill University,

Montreal H3G 1Y6, Canada

e-mail: ursula.stochaj@mcgill.ca

E. Hutter $\cdot$ S. Boridy $\cdot$ M. Juhas $\cdot$ D. Maysinger Department of Pharmacology and Therapeutics, McGill University, Montreal H3G 1Y6, Canada nanospheres, damaged the nucleus at normal growth temperature, several of these defects were further exacerbated by mild hyperthermia. Taken together, the toxicity of gold nanoparticles correlated with changes in nuclear organization and function. These results emphasize that the cell nucleus is a prominent target for gold nanoparticles of different morphologies. Moreover, we demonstrated that RNA synthesis in nucleoli provides quantitative information on nuclear damage and cancer cell survival.

Keywords Gold nanoparticles · Nanoparticle morphology $\cdot$ Protein translocation $\cdot$ Nucleus .

Breast cancer

\author{
Abbreviations \\ BSA Bovine serum albumin \\ CAS Cellular apoptosis susceptibility protein \\ DAPI 4',6-Diamidino-2-phenylindole \\ GNP Gold nanoparticle \\ H3 Histone $\mathrm{H} 3$ \\ ICP-MS Inductively coupled plasma mass spectroscopy \\ LSP Localized surface plasmon resonance \\ MTT 3-(4,5-dimethythiazol-2-yl)-2,5-Diphenyl tetra- \\ zolium bromide \\ NIR Near-infrared \\ NPC Nuclear pore complex \\ STDEV Standard deviation
}

\section{Introduction}

Gold nanoparticles (GNPs) are currently at the center of cancer research. Their potential use in the field ranges from detection by imaging, labeling, or sensing [1-5] to treatment, including drug delivery and phototherapy [6-14]. 
These applications take advantage of the unique optical properties of GNPs, such as strong light scattering, intense absorption, and enhancement of electromagnetic fields. The GNP properties result from the localized surface plasmon resonance (LSPs), i.e., charge density oscillations that are confined to the particles [15]. LSPs, and therefore the physico-chemical properties, depend on the size, shape, and surface of nanoparticles. To date, a large variety of GNPs has been produced in an effort to generate those absorbing in the near-infrared region of light [16] because NIR light does not cause photochemical damage, penetrates deeply within tissues, and provides a better signal-to-noise ratio in photoimaging due to the lack of cellular autofluorescence in this spectral region.

Importantly, the geometry of GNPs, such as rods, shells, cages, or branched particles, not only impacts their LSPs but also alters their interaction with the bio-environment, and is thus critical to nanoparticle uptake and toxicity [1720]. In addition to properties of the GNP, the cell type is also a determining factor in the bio-nano interaction [20].

The growth and proliferation of cancer cells is intimately connected to protein synthesis and thus relies on the ability of cells to produce ribosomes. Nucleoli are specialized compartments in the nucleus that transcribe ribosomal RNA genes and assemble ribosomal subunits [21, 22]. Nucleolar hypertrophy is a hallmark of proliferating cancer cells and has been demonstrated especially in breast cancer tissue and cells [23-28]. Furthermore, nucleolar size correlates with the aggressiveness of breast tumors, and enlarged nucleoli correspond to a poor clinical outcome [23-25], validating the use of nucleoli as targets in cancer therapy [28]. The subcellular redistribution of the nucleolar protein fibrillarin has been linked to autoschizis in cancer cells [29]; fibrillarin was therefore selected to monitor the impact of GNPs on nucleolar organization. Like nucleoli, molecular chaperones, exemplified by the constitutively synthesized hsc70, and the nuclear transporter cellular apoptosis susceptibility protein (CAS [30]) are critical to nuclear functions and essential for cancer cell viability, proliferation, or migration [31-36]. In addition to these proteins, the nuclear lamina and nuclear pore complexes (NPCs) provide sensitive indicators that can be used to monitor changes in cell physiology ([37, 38] and references therein).

At present, the effects of GNPs on subcellular compartments are not fully understood. Since the nucleus is essential for cell survival and proliferation, it is particularly important to define the impact of GNPs on nuclear organization and function. So far, these topics have not been rigorously addressed at the molecular level. Moreover, the potential benefits of combining GNPs with heat treatment have not been examined in a quantitative fashion. However, this information could reveal possible mechanisms that contribute to GNP cytotoxicity. Moreover, this knowledge is mandatory to optimize the use of GNPs. Here, we investigated the effects of gold nanospheres and gold nanoflowers in human breast cancer cells at physiological temperature and upon exposure to mild heat shock. To this end, we focused on multiple aspects of nuclear and nucleolar biology that provide a read-out for changes in tumor cell biology.

\section{Materials and methods}

Preparation and characterization of GNPs

CTAB-coated spherical GNPs $(d=15.6 \pm 1.6 \mathrm{~nm})$ were prepared in two steps. First, an aqueous ice-cold $\mathrm{NaBH}_{4}$ solution $(0.5 \mathrm{ml}, 0.01 \mathrm{M})$ was added to a mixture of aqueous $\mathrm{HAuCl}_{4} * 3 \mathrm{H}_{2} \mathrm{O}(0.125 \mathrm{ml}, 0.01 \mathrm{M})$ and an aqueous solution of CTAB $(4.375 \mathrm{ml}, 0.075 \mathrm{M})$. The seed growth was allowed to proceed for $2 \mathrm{~h}$. In the second step, an aliquot of the aged seed solution $(0.5 \mathrm{ml})$ was added to a solution obtained by adding aqueous CTAB $(8 \mathrm{ml}, 0.10 \mathrm{M})$, aqueous $\mathrm{HAuCl}_{4} * 3 \mathrm{H}_{2} \mathrm{O}(10 \mathrm{ml}, 0.01 \mathrm{M})$, an aqueous ascorbic acid solution $(30 \mathrm{ml}, 0.10 \mathrm{M})$ to $450 \mathrm{ml}$ of water [39]. Immediately upon addition of the seed solution, the sample was mixed gently for $10 \mathrm{~s}$ and then kept undisturbed overnight. The solutions were kept at $27{ }^{\circ} \mathrm{C}$ (in a water bath) throughout the entire procedure to prevent the crystallization of CTAB. At the end of the reaction, the mixture was centrifuged in an Eppendorf centrifuge model 5403 $(6,000 \mathrm{rpm}, 1 \mathrm{~h})$. The residue was redispersed in $5 \mathrm{ml}$ of water. The particles were PEGylated by an overnight incubation with $\alpha$-methoxy- $\omega$-mercapto poly(ethylene glycol) (MeO-PEG-SH, 5,000 g/mol; $0.1 \mathrm{mM}$ ), purified, and concentrated by centrifugation and washing with DI water. The final concentration was determined by ICP-MS (inductively coupled plasma mass spectroscopy); ICP-MS data were acquired using a NexIon 300x (Perkin Elmer) instrument.

\section{Gold nanoflowers}

A 3.0-ml aqueous $\mathrm{HAuCl}_{4}$ (1 wt \%) solution was added to $300 \mathrm{ml}$ of pure ethylene glycol (EG) in a $40{ }^{\circ} \mathrm{C}$ water bath. Then, $6.0 \mathrm{ml}$ of freshly prepared triethanolamine solution ( $2 \mathrm{M})$ was added under mild stirring and the reaction was allowed to run for $1 \mathrm{~h}$. The gold products were collected by centrifugation at 7,000 rpm for $20 \mathrm{~min}$, washed once with water, and redispersed in water [40]. The particles were PEGylated by an overnight incubation as described above, and the final concentration was determined by ICP-MS. Big PEGylated gold nanospheres (methoxy-PEG5000-SH) with a core size of $60 \pm 2 \mathrm{~nm}$ and a mean hydrodynamic diameter of $86 \mathrm{~nm}$ were purchased from Cytodiagnostics, Burlington, ON. 


\section{Instrumentation}

UV-Visible absorption spectra were recorded with an 8452A Agilent photodiode array spectrometer. Transmission electron micrographs of the nanoparticles were obtained using a FEI TECNAI electron microscope operating at $120 \mathrm{kV}$. The supporting grids were Formvar $^{\circledR}{ }_{-}$ covered 200-mesh copper grids. The size of the nanoparticles was determined from electron microscopic images using ImageTool version 3.00 [41]. About 100 particles were measured for each sample.

Growth of MCF7 and HuMEC cells, heat shock, and recovery

MCF7 cells were grown under standard conditions at $37{ }^{\circ} \mathrm{C}$ [42]. Human myoepithelial breast cells (HuMEC; Hs578Bst) were purchased from ATCC and grown in hybri-care medium supplemented with EGF, as recommended by the supplier. Overnight incubation with GNPs $(19.7 \mu \mathrm{g} / \mathrm{ml})$ or vehicle was followed by mild heat shock $\left(1 \mathrm{~h}\right.$ at $\left.43{ }^{\circ} \mathrm{C}\right)$ and recovery at $37^{\circ} \mathrm{C}$ for the times indicated in the figures.

\section{Cytotoxicity and cell viability assays}

The toxicity of gold nanoparticles was assessed by measuring the mitochondrial metabolic activity with thiazolyl blue tetrazolium bromide (MTT). A total of 30,000 MCF7 cells were seeded on each well of a 24-well plate, allowed to attach for $24 \mathrm{~h}$, and incubated with gold nanoparticles in growth medium for $24 \mathrm{~h}$. Cells were then incubated with $500 \mu \mathrm{g} / \mathrm{ml} \mathrm{MTT} \mathrm{in} \mathrm{growth} \mathrm{medium} \mathrm{for} 30-90 \mathrm{~min}$ at $37^{\circ} \mathrm{C}$. The formazan generated was eluted with $350 \mu$ of dimethyl sulfoxide and the optical density was measured at $595 \mathrm{~nm}$ (Bio-Rad Benchmark Microplate Reader, Bio-Rad, Hercules, CA, USA). All MTT assays were performed in triplicates in each experiment, and results were normalized to untreated controls.

\section{Western blotting}

Cells were harvested for quantitative Western blotting as described [43]. Filters were probed with antibodies against phospho-histone H3 (p-Ser10; Cell Signaling, Danvers, MA, USA) and actin (Chemicon; Millipore, Bedford, MA, USA) according to published procedures [44].

\section{Cell fractionation}

Nuclear and cytoplasmic fractions of MCF7 cells treated with vehicle only or GNPs were prepared according to published procedures [44].
Fluorescent labeling of de novo synthesized DNA and RNA

Click technology was employed to detect newly synthesized DNA and RNA. De novo synthesized DNA was labeled with 5-ethynyl-2'-deoxyuridine (EdU) in combination with Alexa Fluor $^{\circledR} 555$ as described by the manufacturer (Invitrogen, Carlsbad, CA, USA). In brief, cells were grown with vehicle or GNPs and then incubated in the presence of $10 \mu \mathrm{m}$ EdU. After $1 \mathrm{~h}$ at $37^{\circ} \mathrm{C}$, samples were fixed and processed for the detection of EdU; nuclei were stained with 4',6-diamidino-2-phenylindole (DAPI). To measure newly synthesized RNA, cells were incubated for $1 \mathrm{~h}$ with $1 \mathrm{mM}$ 5-ethynyluridine (EU). Labeling with Alexa Fluor ${ }^{\circledR}$ 488 was carried according to the manufacturer (Invitrogen).

Two-photon luminescence imaging, confocal microscopy, and quantification of pixel intensities

Two-photon imaging was performed on fixed MCF7 or HuMEC cells mounted in aqueous medium (Fig. 6). All images were acquired with a $63 \times$ (NA 1.4) oil immersion objective. A Zeiss LSM510 (argon laser; $488 \mathrm{~nm}, 0.525 \%$ max intensity) in combination with a BP 500-550 IR filter was used to image Alexa Fluor ${ }^{\circledR} 488$. Gold nanoflowers were detected with a two-photon Ti:sapphire laser (set at $750 \mathrm{~nm} ; 5.0 \%$ of maximum intensity, pulsed) in combination with a BP 390-465 IR filter. Alternatively, images were acquired with a Leica SP8 confocal microscope equipped with a modulable Ti:Sapphire laser that produces 140 -fs pulses at a rate of $80 \mathrm{MHz}$ (set at $2.6 \%$ of maximum intensity). Big gold nanospheres were visualized with hybrid avalanche photodiodes; emission light was collected between 560 and $630 \mathrm{~nm}$, and the multiphoton laser wavelength was tuned to $700 \mathrm{~nm}$. For gold nanoflowers, hybrid avalanche photodiodes collected emission light between 390 and $460 \mathrm{~nm}$, while the multiphoton laser wavelength was tuned to $750 \mathrm{~nm}$. Alexa Fluor ${ }^{\circledR} 488$ was detected by photomultiplier tubes (PMTs); following excitation with a solid-state laser line at $488 \mathrm{~nm}$; emission light was collected between 500 and $600 \mathrm{~nm}$. No background fluorescence of cells was detected under these settings (not shown).

3D surface rendering of image stacks was performed with Imaris software (Bitplane, Zurich Switzerland). Confocal imaging for all other figures followed published procedures [45]. Secondary antibodies were purchased from Jackson ImmunoResearch. For image quantification, immunostaining was carried out with secondary antibodies pre-adsorbed against human proteins. All images of a data set were acquired at identical settings of the microscope. Protocols for computer-based fluorescence measurements in nuclei and nucleoli have been described previously 
in detail $[45,46]$. In brief, nucleoli were demarcated by combining the median filter images for CAS and fibrillarin (see [47] for details). EdU incorporation was quantified for images collected with a Zeiss LSM510 confocal microscope, using a $20 \times$ objective (NA 0.5 ) and a zoom of 2 [45]. Pixel intensities were determined for all nuclei; nuclear compartments were demarcated by DAPI staining.

\section{Statistics}

Comparisons between control and treated groups were performed by one-way ANOVA combined with Bonferroni post-analysis. Differences were considered significant, if $p$ values were smaller than $0.05 ; * * p<0.01 ; * p<0.05$.

\section{Results}

Characterization of gold nanospheres and gold nanoflowers

Nanoparticle size and shape are expected to influence the nano-bio interactions from uptake to intracellular behavior [20]. Moreover, the spectral characteristics of nanoparticles are important for potential applications such as photothermal therapy or imaging. The three types of PEGylated GNPs used here were different in several aspects. The small gold nanospheres had a very regular shape (Fig. 1),
Fig. 2 Impact of GNPs on the nuclear and nucleolar organization of cancer cells. MCF7 cells incubated with vehicle, small gold nanospheres (small spheres), nanoflowers (flowers), or big gold nanospheres (big spheres) were analyzed in the absence of heat (control), after heat shock, or $2 \mathrm{~h}$ recovery from heat stress. Hsc70, fibrillarin, or CAS were located by indirect immunofluorescence and images were acquired by confocal microscopy with identical settings for each antigen. Nucleolar fluorescence was quantified following established protocols [45]. Nuclei were stained with DAPI; size bar is $20 \mu \mathrm{m}$. Several of the irregularly shaped nuclei in GNP-treated samples are marked by arrowheads. Pixel intensities/area were measured for at least 66 nucleoli (a minimum of 21 cells) for each data point and experiment. Bar graphs depict the average + STDEV of two independent experiments. $V$ vehicle, $S$ small gold nanospheres, $F$ gold nanoflowers, $B$ big gold nanospheres. Results are normalized to controls which were incubated with vehicle alone

narrow size distribution $(2 r=15.6 \pm 1.6 \mathrm{~nm})$, and narrow absorption peak $(518 \mathrm{~nm})$, while the gold nanoflowers were of irregular shape, larger size, and highly polydisperse (40$120 \mathrm{~nm}$ ), with an absorption well extended into the NIR region [48, 49]. Big regularly shaped gold nanospheres with a hydrodynamic diameter of $86 \mathrm{~nm}$ were employed to identify effects that are caused by large particle size.

\section{Impact of GNPs on cell survival and proliferation}

We selected the human breast tumor cell line MCF7 for our experiments because it is widely used to study breast
Fig. 1 Characterization of gold nanoparticles. a, b Transmission electron microscopic images (TEM), c asymmetric field flow fractionation (AFFF) results, and $\mathbf{d}$ surface plasmon extinction spectra of PEGylated gold nanospheres (a and black solid line) and nanoflowers (b and red solid line). The TEM images show the narrow size distribution and regular shape of the small gold nanospheres (a) and the polydisperse large gold nanoflowers (b). The AFFF results in part (c) confirm the difference in size and polydispersity of PEGylated small gold nanospheres and nanoflowers. $\mathbf{d}$ Small gold nanospheres possess a well-defined absorption peak at $518 \mathrm{~nm}$, which contrasts the broad and lower energy absorption of gold nanoflowers
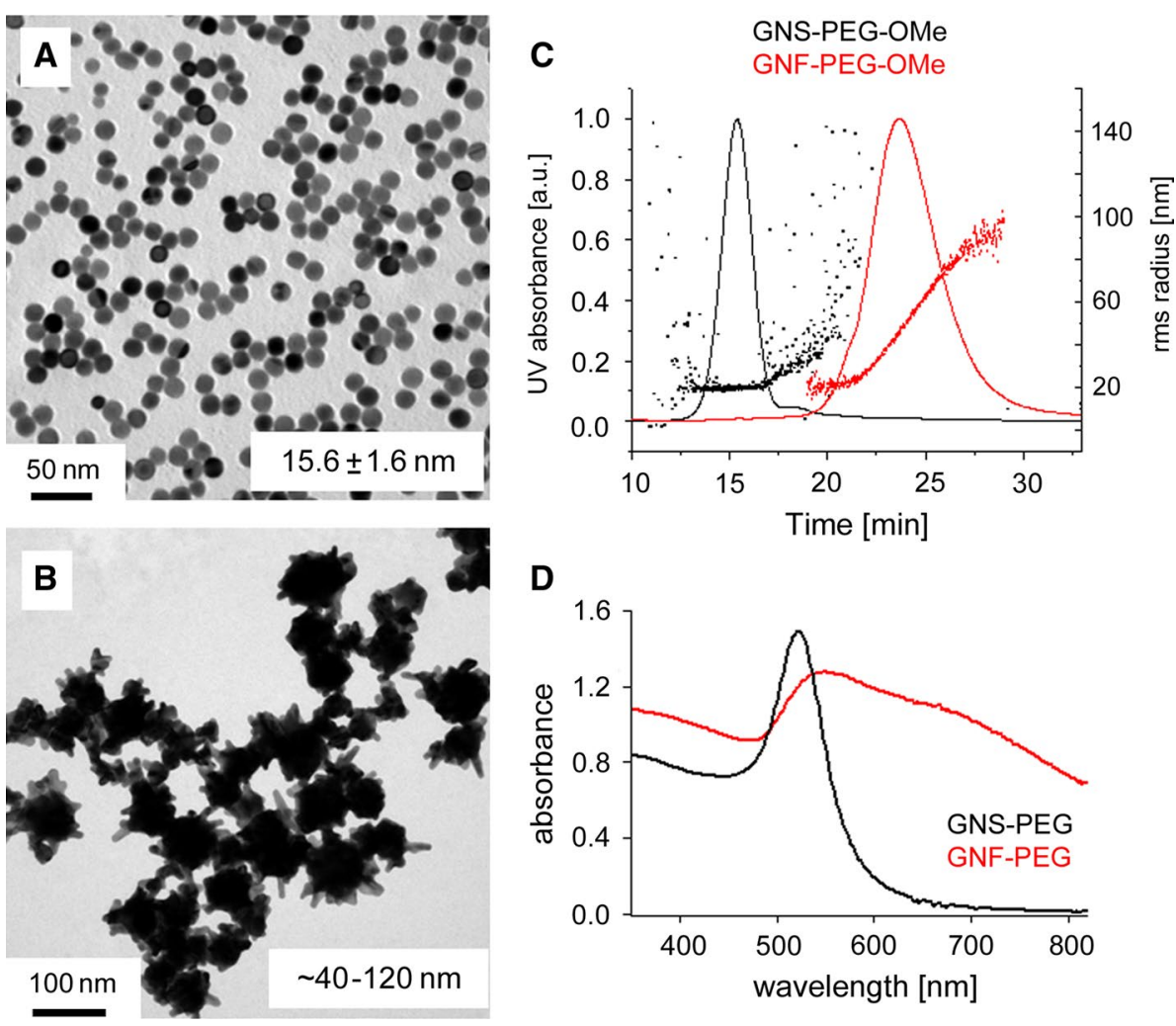

D

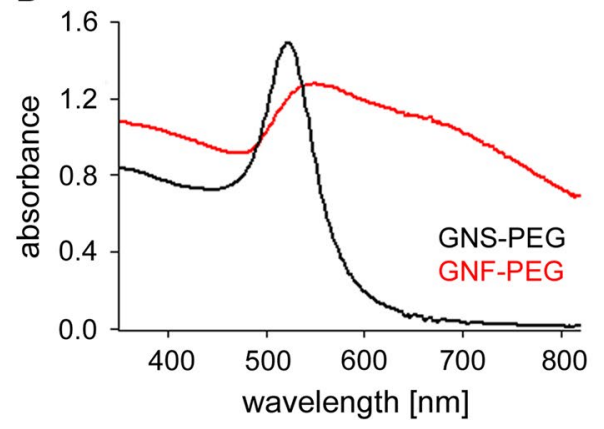



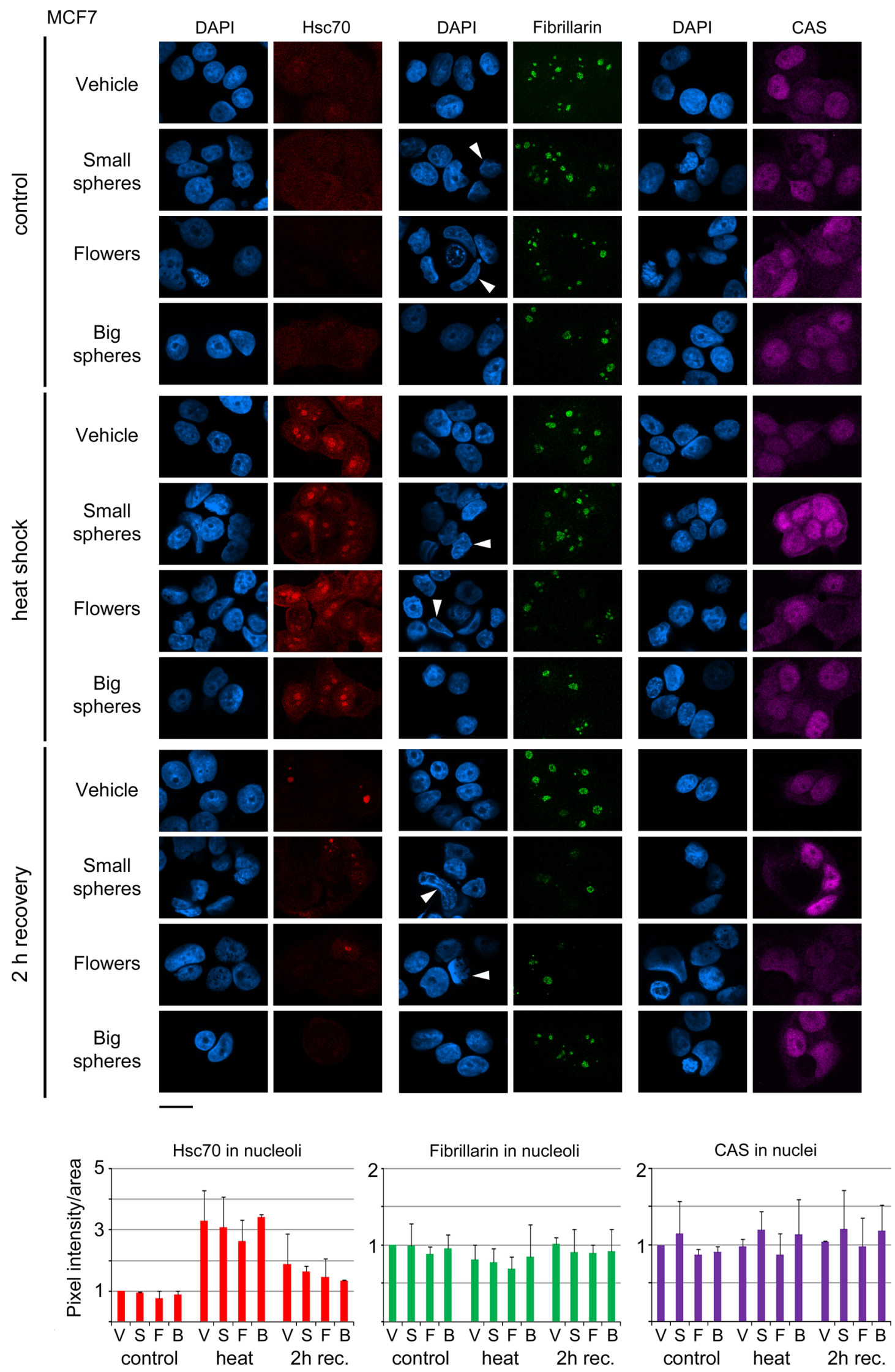
cancer, and furthermore represents an excellent model to examine the functional organization of nucleoli (see below) in tumor cells [50]. Our initial experiments defined the impact of gold nanospheres and nanoflowers on MCF7 cells by examining the metabolic activity of mitochondria and cell proliferation (Suppl. Fig. 1). Following a 24-h incubation with GNPs, small gold nanospheres $\left(\mathrm{LD}_{50}=13 \mu \mathrm{g} / \mathrm{ml}\right.$ $\mathrm{Au})$ were more toxic than gold nanoflowers $\left(\mathrm{LD}_{50}=83 \mu \mathrm{g} /\right.$ $\mathrm{ml} \mathrm{Au}$; Suppl. Fig. 1A). Unlike small gold nanospheres and nanoflowers, big gold nanospheres had little effect on mitochondrial activity.

The toxicity of GNPs could be linked to GNP-induced changes in proliferation; this hypothesis was tested by quantifying two separate parameters, histone H3 phosphorylation (Suppl. Fig. 1B; phospho-H3) and de novo DNA synthesis. Ser10 of $\mathrm{H} 3$ is phosphorylated in mitotic cells, and in the absence of heat, small gold nanospheres increased the signal for phospho-H3. However, the combination of heat and gold nanospheres reduced this $\mathrm{H} 3$ modification, in particular after a 24 -h recovery period, indicating that a smaller proportion of cells underwent mitosis. Big gold nanospheres led to a clearly different outcome; they increased the level of phospho-H3 for all conditions.

Cells in S phase can be detected with EdU; this compound is incorporated into newly synthesized DNA and can be visualized with a fluorescent tag (Suppl. Fig. 1B). In the absence of heat stress, all GNPs reduced the number of cells in S-phase; however, the impact of big gold nanospheres was minor. After heat shock and $2 \mathrm{~h}$ recovery, gold nanoflowers increased the number of cells incorporating EdU, but this effect was only transient. Following a 24-h recovery phase, small gold nanospheres markedly diminished the number of cells with de novo DNA synthesis.

Collectively, these results support the idea that in our model system of cultured breast cancer cells, small gold nanospheres, nanoflowers, and heat shock have pronounced effects on mitochondrial activity and cell proliferation. When combined with mild hyperthermia, small gold nanospheres further diminished mitosis and DNA synthesis, whereas gold nanoflowers reduced the proportion of mitotic cells. Since GNPs can be used for thermal killing of cancer cells [51] and nuclei are crucial for cell survival and proliferation, it was our objective to examine how GNPs or the combination of heat and GNPs alter the nuclear biology in MCF7 cells.

GNPs combined with mild hyperthermia alter the subcellular distribution of hsc70, fibrillarin, and CAS

A common feature shared by hsc70, fibrillarin, and CAS is their sensitivity to stress; all of the proteins relocate within the cell following an exposure to heat shock [42, 45, $52,53]$. As their subcellular relocation and the biological
Fig. 3 Effect of GNPs on human non-cancer breast cells. HuMEC were treated with vehicle, small gold nanospheres (small spheres), nanoflowers (flowers), or big gold nanospheres (big spheres) and analyzed as described for Fig. 2. Nuclei were visualized with DAPI; size bar is $20 \mu \mathrm{m}$. Fluorescence intensities/area were quantified for at least 106 nucleoli (a minimum of 52 cells) for each data point and experiment. Bar graphs show the average + STDEV of two independent experiments. $V$ vehicle, $S$ small gold nanospheres, $F$ gold nanoflowers, $B$ big gold nanospheres. Results are normalized to vehicle-treated controls

activities of nucleoli can be measured in a quantitative fashion $[42,45]$, these criteria were employed here to monitor the effect of GNPs.

In one possible scenario, GNPs interfere with the stress response and thus prevent the repair of heat-induced damage. To test this hypothesis, we assessed the impact of heat on MCF7 cells incubated with vehicle, small gold nanospheres, nanoflowers or big gold nanospheres. Figure 2 shows that small gold nanospheres and nanoflowers, either alone or combined with a mild heat shock at $43{ }^{\circ} \mathrm{C}$, changed the nucleolar and nuclear morphology, as both types of particles induced the formation of nuclei with crescent or irregular shape (Fig. 2, arrowheads). Under the same conditions, big gold nanospheres had little effect on these parameters.

To determine whether these morphological differences correlate with the subcellular distribution of marker proteins that are relevant to nuclear organization and function, we focused on the chaperone hsc70, the nucleolar protein fibrillarin, and the nuclear transporter CAS.

The nucleolar accumulation of hsc70 is a well-established heat shock response that is likely linked to the proper organization and function of nucleoli $[42,53,54]$. When compared to vehicle or other GNPs, gold nanoflowers led to a small reduction of nucleolar hsc70 after heat shock (Fig. 2). For control and GNP-treated cells, the heatinduced concentration of hsc70 in nucleoli was only transient; and the nucleolar accumulation was diminished after $2 \mathrm{~h}$ of recovery. Interestingly, all GNPs somewhat reduced the amount of hsc70 in nucleoli at this time point.

As small gold nanospheres and nanoflowers altered the nuclear morphology, we further evaluated the organization of nucleoli with the marker protein fibrillarin (Fig. 2). While the nucleolar concentration of fibrillarin was reduced by heat, small gold nanospheres and nanoflowers slightly enhanced the loss of fibrillarin from nucleoli. The GNPinduced morphological changes of nuclei and nucleoli persisted after $2 \mathrm{~h}$ of recovery in cells incubated with small gold nanospheres or nanoflowers (Fig. 2). At the same time, the nucleolar fibrillarin concentrations were restored to non-stress conditions.

The nuclear transporter CAS provides an additional stress sensor. In response to severe heat shock, CAS 

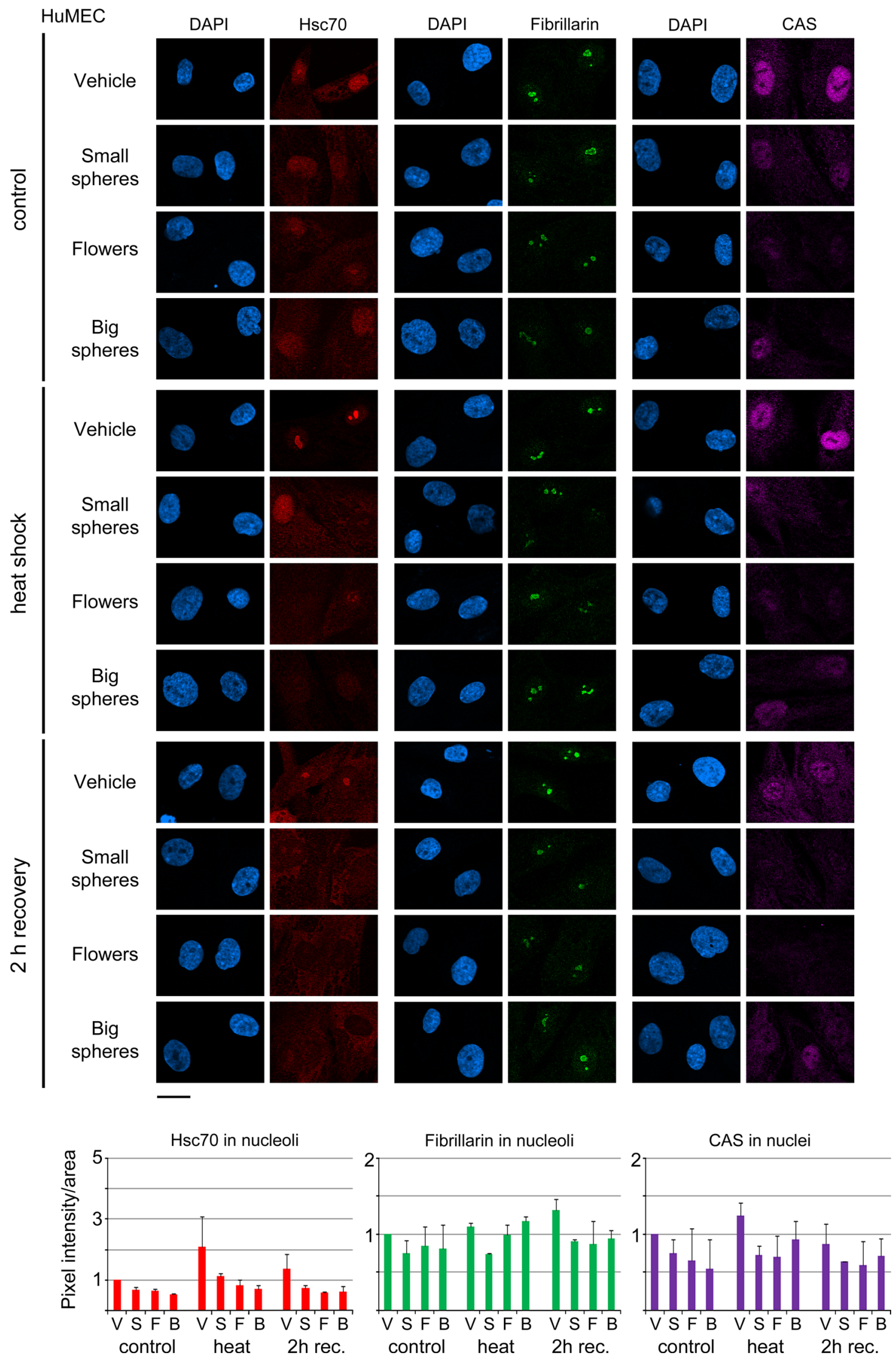
accumulates in the nucleoplasm [52], where it participates in chromatin organization and transcription [34]. All GNPs had minor effects on CAS concentrations in the nucleus (Fig. 2), and these effects were variable. Although not significant, small gold nanospheres had the tendency to increase the concentration of CAS in nuclei.

To successfully employ GNPs for cancer therapy, it is important to limit damage in the surrounding healthy tissue. We addressed this point by analyzing normal human breast cells (HuMEC) under the same conditions (Fig. 3). As compared to MCF7 cells, four major differences were observed for HuMEC. First, none of the GNPs caused prominent alterations in nuclear morphology. Second, independent of GNPs, the heat-induced nucleolar accumulation of hsc70 was much less pronounced. At the same time, GNPs reduced nucleolar hsc70 under all conditions. Third, small gold nanospheres had the strongest effects on nucleolar fibrillarin. Fourth, nuclear CAS concentrations were more affected by all GNPs tested. Thus, HuMEC and MCF7 cells responded differently to GNPs; these differences were considerable for hsc70.

In addition to the measurements of fluorescence intensities in nuclei, we also determined the percentage of nuclei that can be labeled with antibodies against fibrillarin (Fig. 4). In MCF7 cells, small gold nanospheres and
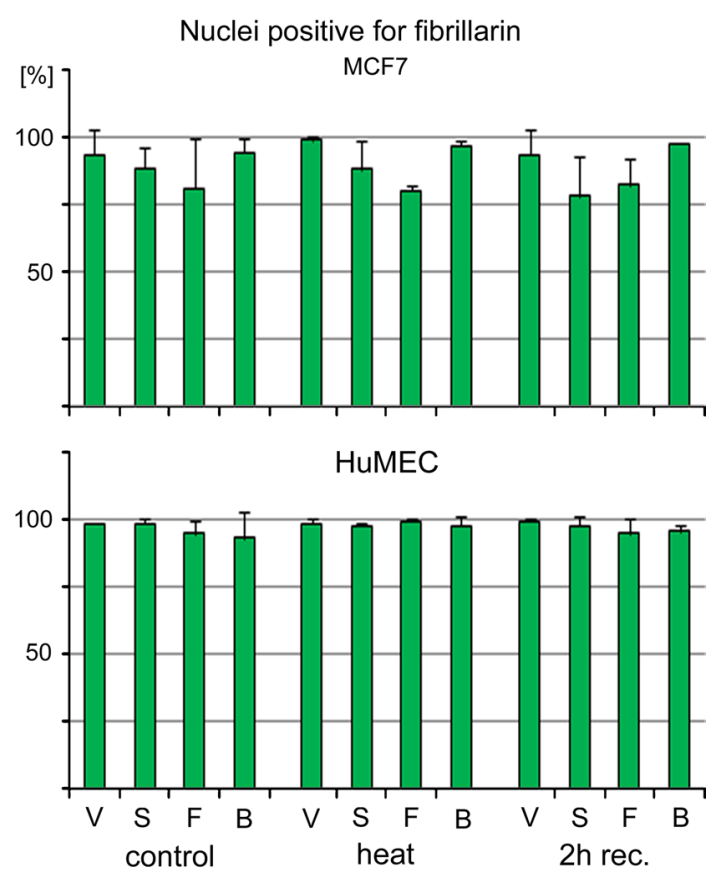

Fig. 4 Staining of MCF7 and HuMEC nuclei with antibodies against fibrillarin. The percentage of nuclei that are stained with antibodies against fibrillarin was determined for MCF7 cells and HuMEC. Samples were treated as described for Figs. 2 and 3, and nuclei positive for fibrillarin staining were assessed in two independent experiments. Original data are shown as average + STDEV. $V$ vehicle, $S$ small gold nanospheres, $F$ gold nanoflowers, $B$ big gold nanospheres nanoflowers somewhat reduced the number of nuclei that were immunopositive for fibrillarin, but big gold nanospheres had no effect. In contrast to MCF7 cells, GNPs had little effect on the percentage of nuclei that were positive for fibrillarin staining in HuMEC. It should be noted that the results in Figs. 2, 3, and 4 are not comparable; Fig. 4 does not provide information on the strength of the fluorescence signal.

In summary, while there was variability between individual experiments, small gold nanospheres and nanoflowers clearly altered the nuclear and nucleolar morphology of MCF7 cells. These GNPs also caused subtle changes in the subcellular distribution of hsc70, fibrillarin, and CAS. For all of the markers assessed, HuMEC displayed a different pattern of changes. Interestingly, GNPs had little impact on the nuclear and nucleolar morphology.

The nuclear lamina and NPCs are sensitive to the treatment with GNPs and hyperthermia

Data presented in Fig. 2 suggested that MCF7 cells are particularly vulnerable to small gold nanospheres and nanoflowers. To further characterize the impact of GNPs, MCF7 cell morphology and compartmentalization was analyzed with antibodies against NPCs (mab414), the nuclear lamina (lamin A), or the predominantly cytoplasmic protein lactate dehydrogenase (LDH). Cells were examined in the absence of heat stress (control), with heat shock and after a 2-h recovery period (Fig. 5). For all time points, MCF7 cells treated with small gold nanospheres or nanoflowers displayed major changes in nuclear envelope and lamina organization, and irregularly shaped nuclei prevailed during recovery. This was in contrast to big gold nanospheres, which were comparable to vehicle-treated controls. Taken together, small gold nanospheres and gold nanoflowers affected the proper compartmentalization of MCF7 cells and modulated stress responses; this correlated with extensive damage to nuclear and nucleolar organization.

Gold nanospheres and gold nanoflowers associate with nuclei

To begin to understand the mechanisms that underlie the GNP-dependent changes in nuclear organization, it was important to examine their subcellular distribution and, in particular, a possible interaction with nuclei.

To this end, we selected methods that are appropriate for the detection of gold nanospheres and nanoflowers. We hypothesized that the relatively small size of gold nanospheres could potentially provide slow access to the nucleus by diffusion through NPCs, whereas gold nanoflowers and big gold nanospheres exceed the diffusion channel of the nuclear pore by far. Indeed, small gold nanospheres were 
Fig. 5 Gold nanospheres and nanoflowers reorganize the nuclear membrane and lamina. MCF7 cells incubated with vehicle, small gold nanospheres (small spheres), gold nanoflowers (flowers), or big gold nanospheres (big spheres) were analyzed by indirect immunofluorescence with antibodies against nuclear pore complexes (mab414), the nuclear lamina (lamin A) or the cytoplasmic protein lactate dehydrogenase [44]. The staining was carried out for controls, heat-shocked cells and after a 2 -h recovery period. Panels show single staining or merged images; size bar is $20 \mu \mathrm{m}$

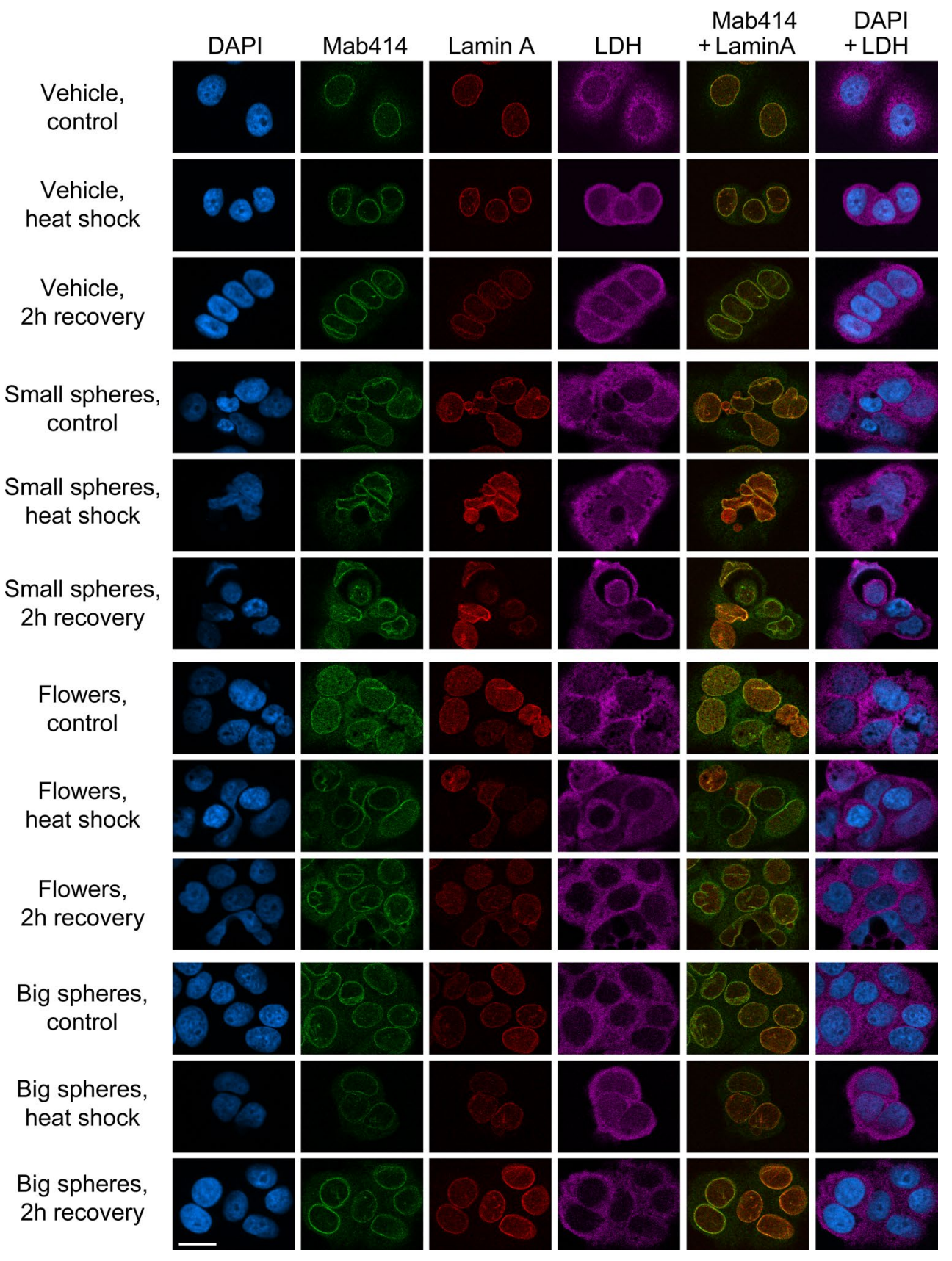

detected by transmission electron microscopy in both cytoplasmic and nuclear fractions (Suppl. Fig. 2). To evaluate their subcellular distribution, gold nanoflowers and big gold nanospheres were localized together with fibrillarin or lamin A in unstressed controls, heat-shocked cells, and upon 2-h recovery (Fig. 6). Notably, while gold nanoflowers associated with the nucleus and cytoplasm under all conditions, the distribution of fibrillarin and lamin A was particularly affected after heat shock and during the recovery. Big gold nanospheres were also present on the surface of the nucleus, but only few were detected inside the nuclei of MCF7 cells. In HuMEC, gold nanoflowers and big gold nanospheres associated with nuclei (Fig. 6), and the nuclear association of big gold nanospheres was enhanced by heat shock.

Based on the nucleolar marker fibrillarin and the nuclear envelope marker lamin A, Fig. 6 suggests that the combination of heat stress and gold nanoflowers led to severe nucleolar fragmentation and lamina disorganization in MCF7 cells. These changes in nuclear organization persisted through a 2 -h recovery period. The mechanisms by which gold nanoflowers enter nuclei are presently not known, but Fig. 6 clearly shows their presence in the nuclear interior. It is therefore plausible that the nuclear 


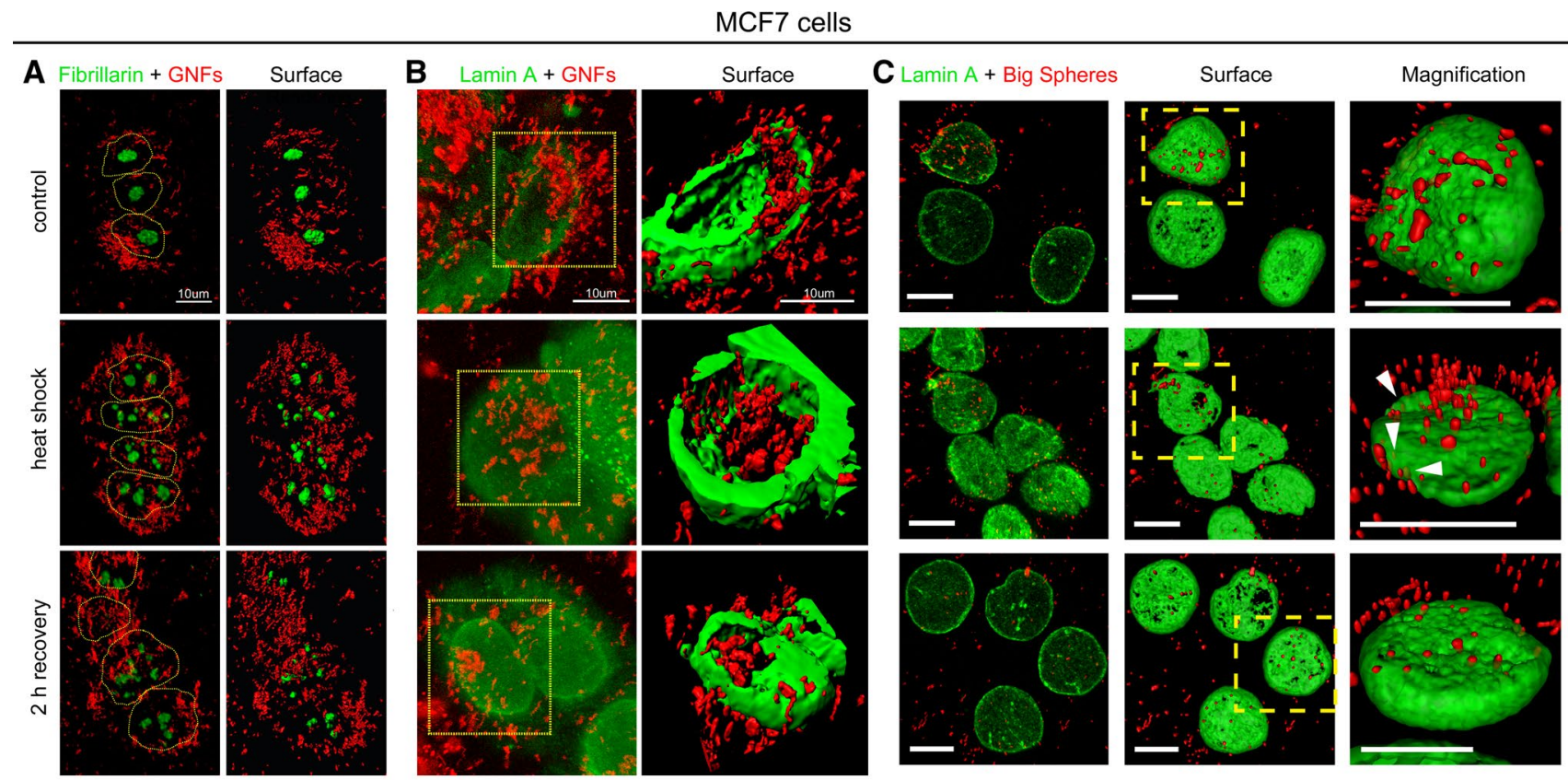

HUMEC
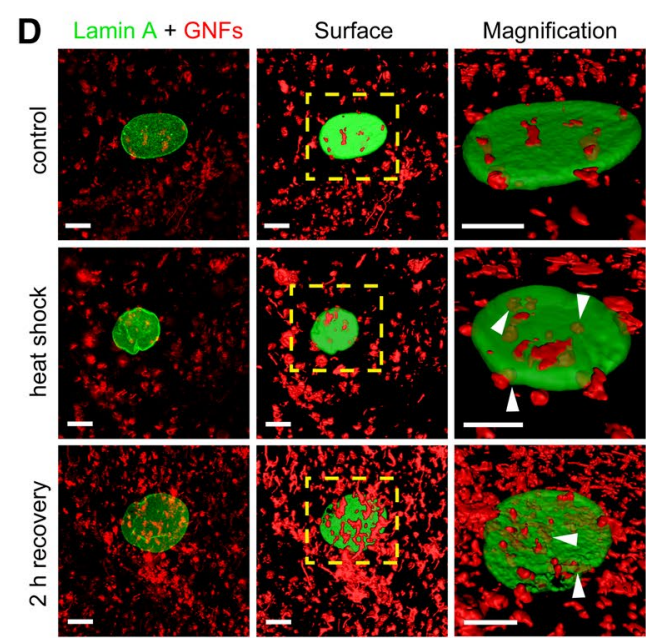

Fig. 6 a-c Gold nanoflowers disrupt the nucleolar and lamina organization in heat-shocked MCF7 cells. MCF7 cells treated overnight with GNPs were exposed to a 1-h heat shock at $43{ }^{\circ} \mathrm{C}$, followed by 2 -h recovery at $37{ }^{\circ} \mathrm{C}$. Cells were fixed, stained with antibodies against fibrillarin or lamin $\mathrm{A}$, and confocal images were acquired as described in the "Materials and methods" section. Gold nanoflowers (GNFs) and big gold nanospheres (big spheres) are pseudocolored in red. Panels show 3D projections of confocal z-stacks. Based on 3D projections of the fluorescent images, surfaces were generated with Imaris software; magnified views are shown as indicated. a MCF7 cells were incubated with gold nanoflowers and fibrillarin was located by indirect immunofluorescence; nuclei are demarcated by dotted lines. $\mathbf{b}$ Cells treated with gold nanoflowers or $\mathbf{c}$ big gold nanospheres

association of gold nanoflowers led to morphological disruption and structural damage in MCF7 cells. On the other hand, the interaction of big gold nanospheres with heat-shocked HuMEC nuclei likely impeded the nucleolar localization of hsc70.

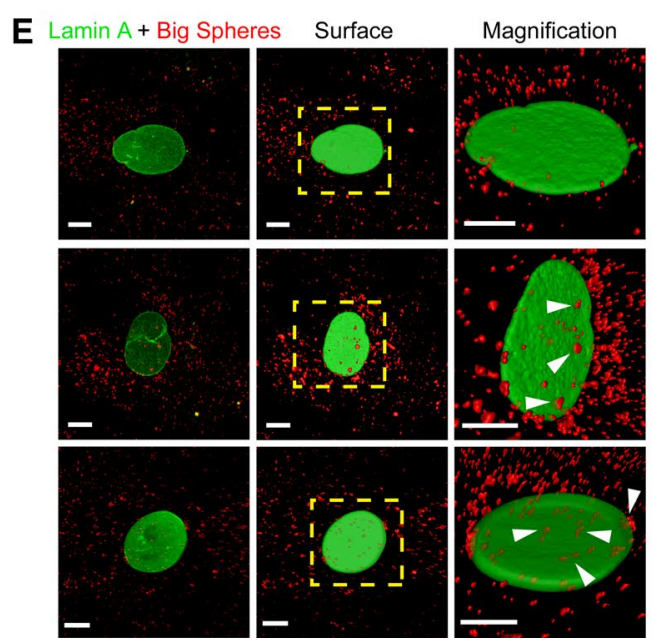

were stained for lamin A. Note that gold nanoflowers associated with nuclei and can be detected in the nuclear interior. Some big gold nanospheres also appear to be located in the nucleus (arrowheads). In cells treated with gold nanoflowers, the distribution of fibrillarin and lamin A indicates severe nucleolar fragmentation and lamina disorganization in response to heat shock; they persist during the recovery period. d, e Association of gold nanoflowers and big gold nanospheres with HuMEC nuclei. The impact of gold nanoflowers and big gold nanospheres on lamin A in HuMEC was analyzed as described for MCF7 cells. The possible presence of GNPs in HuMEC nuclei is marked by arrowheads. All results are representative of at least three independent experiments; size bars are $10 \mu \mathrm{m}$

Small gold nanospheres and nanoflowers inhibit nucleolar RNA synthesis in MCF7 cells

Since our results demonstrated that small gold nanospheres and gold nanoflowers induced significant changes in 


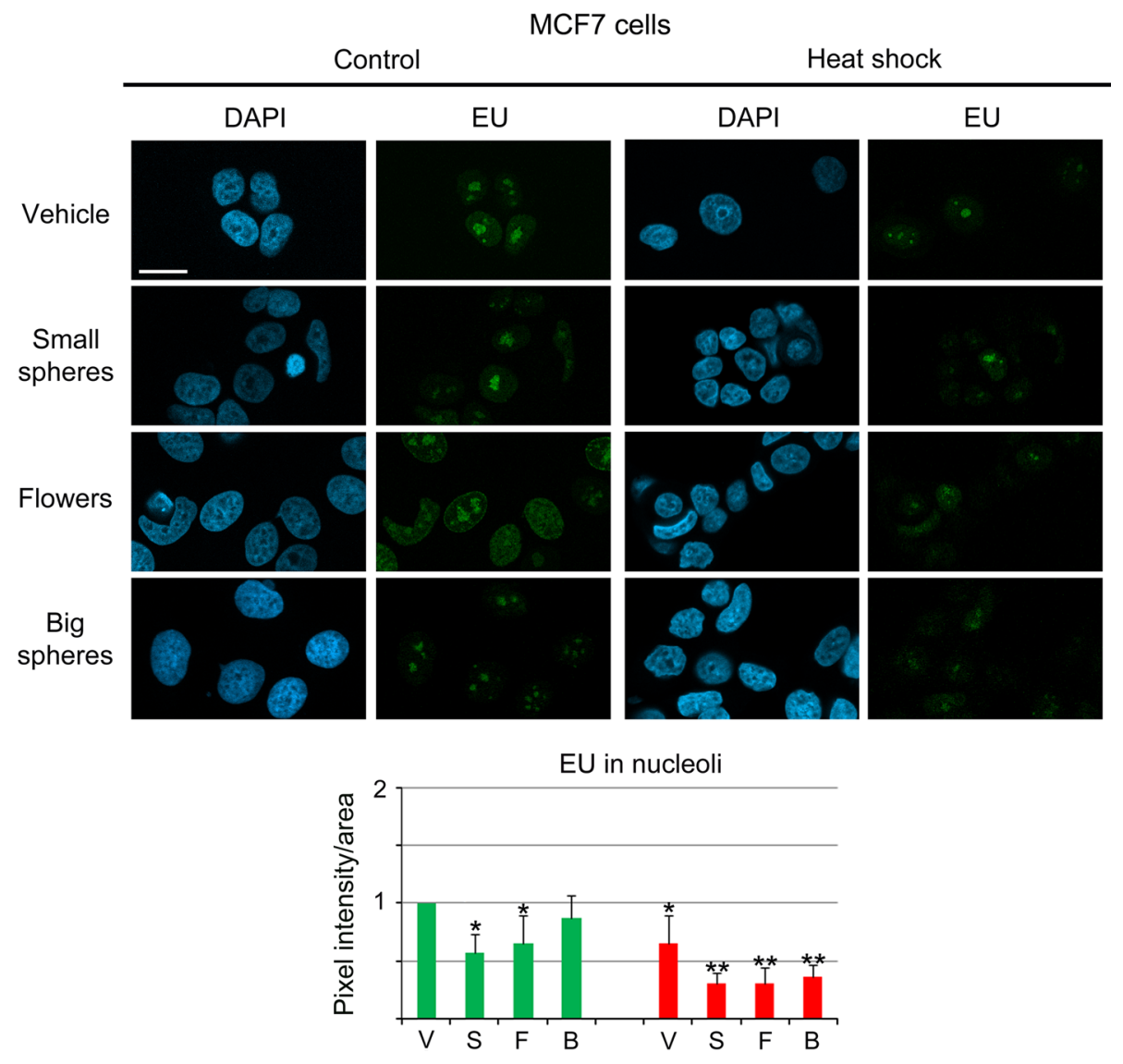

Fig. 7 Small gold nanospheres and gold nanoflowers reduce de novo RNA synthesis in nucleoli of MCF7 cells. MCF7 cells were treated overnight with vehicle $(V)$, small gold nanospheres $(S)$, nanoflowers $(F)$, or big gold nanospheres $(B)$. Cells were then incubated with 5-ethynyluridine (EU) at $37{ }^{\circ} \mathrm{C}$ ( green bars) to label newly synthesized RNA. For comparison, de novo RNA synthesis was determined during a 1-h heat shock at $43{ }^{\circ} \mathrm{C}$ (red bars). Pixel intensities/area were measured in at least 50 nucleoli for each data point and experi-

nuclear and nucleolar organization, it was important to test whether these alterations were accompanied by changes in nucleolar function. To this end, de novo RNA synthesis in the nucleolus was quantified for different conditions for MCF7 cells (Fig. 7). In MCF7 cells, small gold nanospheres or gold nanoflowers decreased significantly the RNA synthesis in nucleoli, whereas big gold nanospheres had little effect. Moreover, the inhibition of nucleolar RNA synthesis was greatly enhanced by mild hyperthermia. When combined with heat shock, all of the GNPs exacerbated the loss of nucleolar RNA synthesis.

To obtain further evidence for the GNP-induced changes in nucleolar function, 3D reconstructions were performed for the compartments that produced new RNA (Fig. 8). When compared to the treatment with vehicle or big gold nanospheres, small gold nanospheres and gold nanoflowers led to striking changes. Both GNPs caused a profound reorganization of the compartments that synthesize new ment [45]. The bar graph depicts the average + STDEV of 3-6 independent experiments. Note that heat shock, small gold nanospheres, and nanoflowers significantly inhibited RNA synthesis in nucleoli of MCF7 cells, even in the absence of hyperthermia. Significant differences were identified by one-way ANOVA/Bonferroni test; the vehicle-treated non-stress sample served as reference $\left({ }^{*} p<0.05\right.$; $* * p<0.01)$. Size bar is $20 \mu \mathrm{m}$

RNA, in line with the idea that the structural and functional organization of nucleoli is severely damaged by gold nanospheres and gold nanoflowers in MCF7 cells.

HuMEC nucleoli showed a remarkably different response to GNPs (Fig. 9), as all treatments stimulated nucleolar RNA production. In particular, hyperthermia and big GNPs increased significantly de novo RNA synthesis in nucleoli.

\section{Discussion}

Gold nanoparticles have emerged as powerful tools with many applications in nanomedicine, including cellular imaging, biomedical diagnostics, and theranostics. Despite these diverse applications, little is known about the biological effects of GNPs at the subcellular level, such as the nucleus. In particular, the impact of gold nanoparticles on the nucleolus has not been investigated so far. 
Fig. 8 Small gold nanospheres and gold nanoflowers reorganize the nucleolar subcompartments that synthesize RNA de novo. MCF7 cells were incubated with vehicle or GNPs at $37^{\circ} \mathrm{C}$ as described for Fig. 7 . Confocal stacks were acquired and surface rendering was performed to visualize new RNA production. DNA was stained with DAPI; newly synthesized RNA was labeled with EU. Note that small gold nanospheres and gold nanoflowers disturb the nucleolar subcompartments that transcribe rDNA

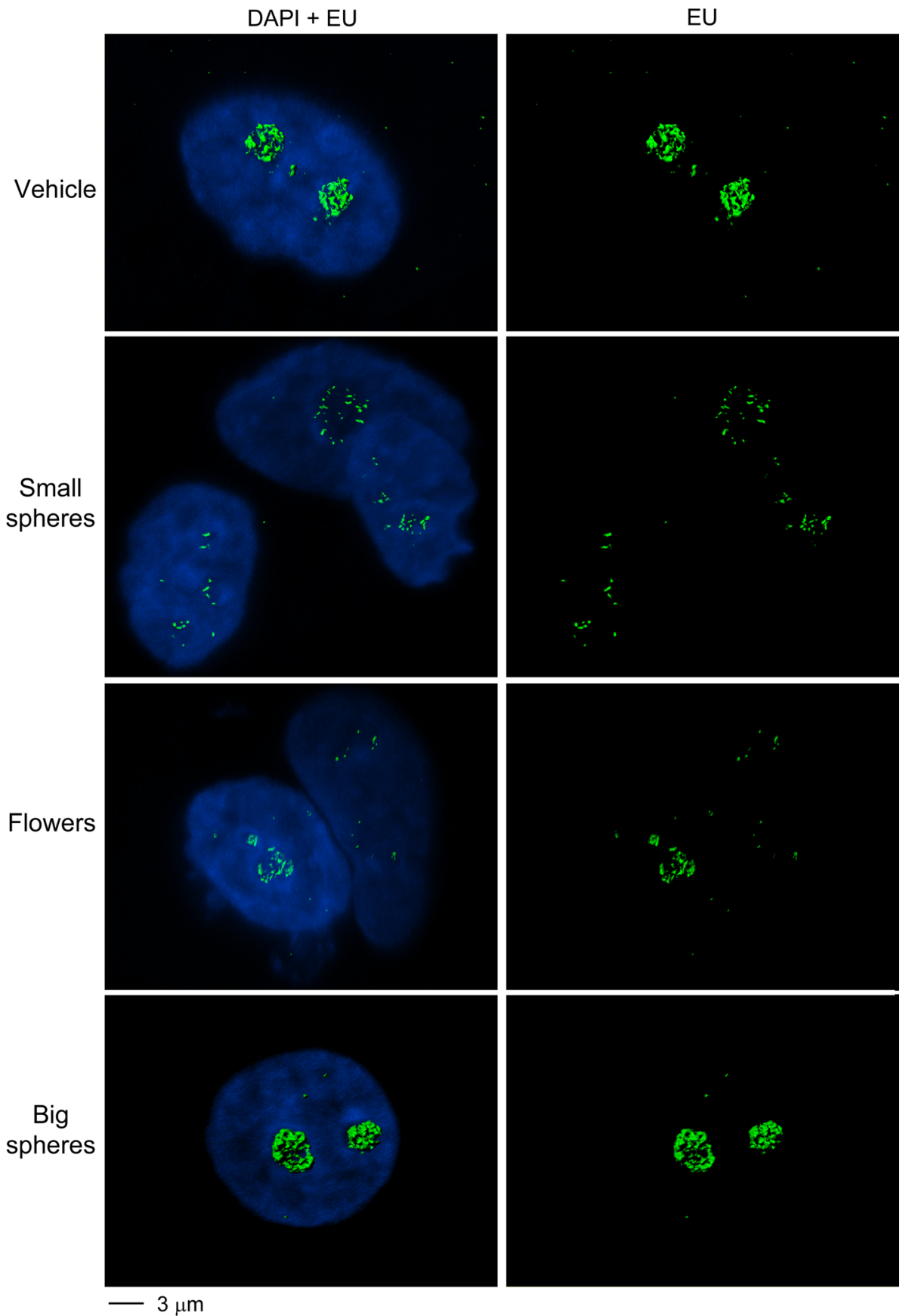

Using MCF7 breast cancer cells as a model system, we assessed GNP-induced changes in cell physiology. Several parameters of nuclear biology were examined, including nuclear morphology, organization and function. Importantly, all of these parameters were sensitive to GNP treatment (Fig. 10), and at least some of the detrimental effects were further amplified by mild heat shock. For example, GNP-dependent irregularities in nuclear shape, which correlated with a reorganization of nuclear envelopes and laminae, became more prominent in heat-treated cells. However, the effect of GNPs went beyond changes in nuclear morphology, as the heat shock response, nucleolar organization, and function were altered as well. As such, GNPs modulated the proper location of hsc70 and CAS, reorganized nucleoli, and aggravated heat-induced nucleolar fragmentation. Our analyses of transcription in nucleoli emphasize that the GNP-induced changes in morphology and subcellular organization also impinge on nucleolar function. A simplified model depicted in Fig. 10 integrates these observations; it proposes that unlike the transient perturbations caused by mild heat shock [53], the injuries produced by small gold nanospheres and gold nanoflowers are 


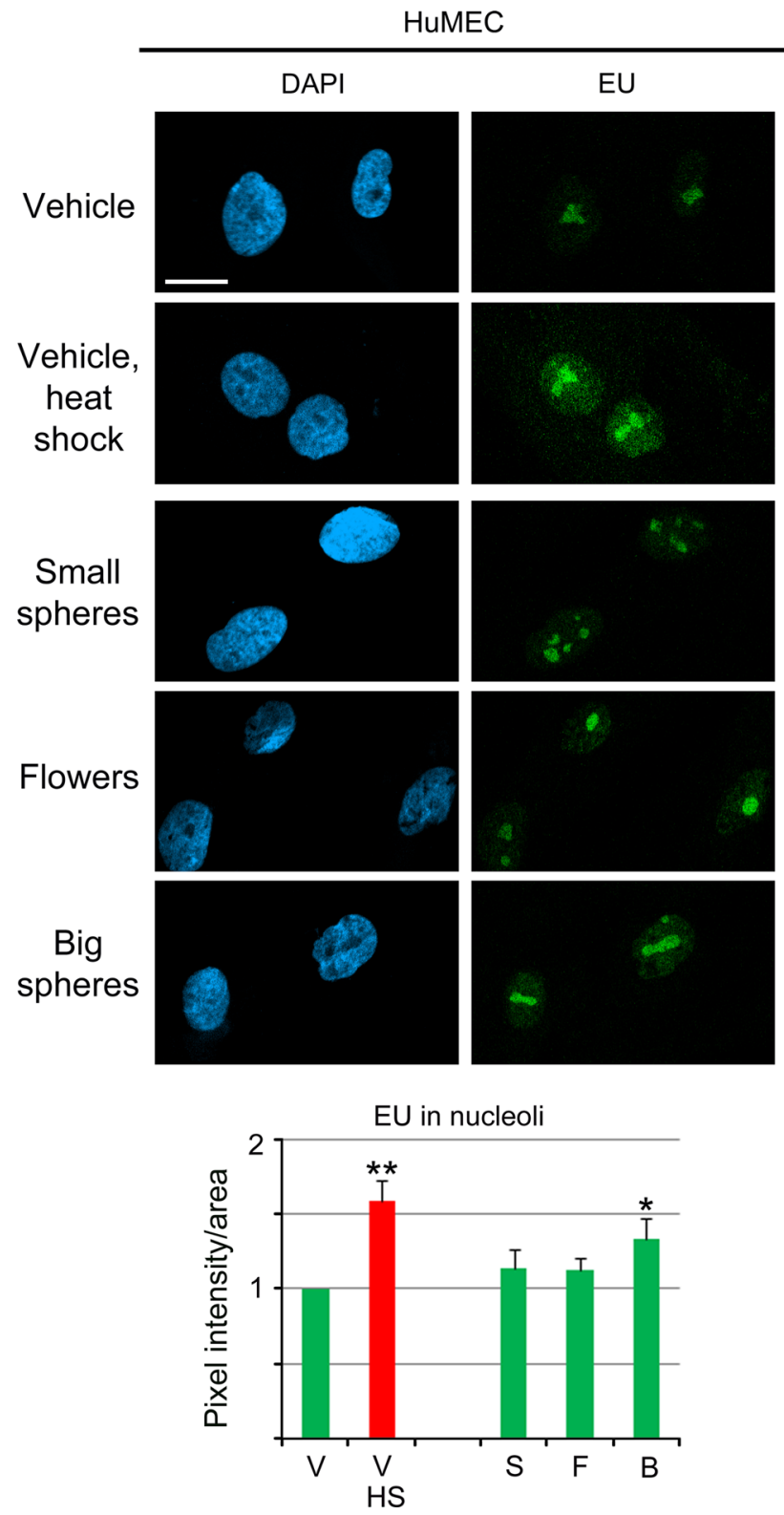

Fig. 9 Effect of GNPs on nucleolar RNA synthesis in HuMEC. EU incorporation was quantified in HuMEC incubated with vehicle or GNPs at $37{ }^{\circ} \mathrm{C}$ (green bars) as described for Fig. 7. For comparison, de novo RNA synthesis was measured for vehicle-treated samples at $43{ }^{\circ} \mathrm{C}$ ( red bar). Significant differences were identified by one-way ANOVA/Bonferroni test; the vehicle-treated non-stress sample served as reference $(* p<0.05 ; * *<0.01)$. Size bar is $20 \mu \mathrm{m}$. A significant increase in new nucleolar RNA synthesis was detected for cells exposed to heat shock or big gold nanospheres

persistent. Our model also incorporates the differences we identified between small gold nanospheres and nanoflowers in their capacities to modulate stress responses and the functional organization of nuclei and nucleoli.

Under the conditions used in the present study, small nanospheres outperformed gold nanoflowers. This applies in particular to the loss of cell viability and changes in

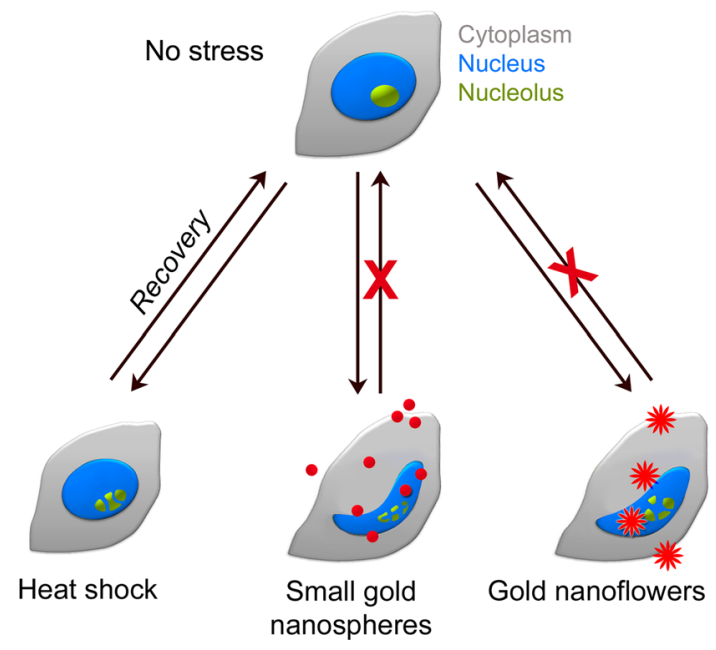

Fig. 10 Simplified model for the impact of heat shock, small gold nanospheres, and gold nanoflowers on nuclei and nucleoli. Mild heat shock alters the morphology and function of nucleoli (green); these changes are reversible when cells recover from stress. By contrast, small gold nanospheres and nanoflowers cause severe damage, leading to changes in the morphology of nuclei (blue), nucleoli and nucleolar function. This GNP-induced damage is persistent and further exacerbated by heat

Table 1 Effects of GNPs on MCF7 cells

\begin{tabular}{lll}
\hline Parameter & Condition & Result \\
\hline Mitochondrial metabolic & Small gold nanospheres & $\downarrow \downarrow \downarrow$ \\
activity & Gold nanoflowers & $\downarrow \downarrow$ \\
& Big gold nanospheres & $\leftrightarrow$ \\
De novo RNA synthesis in & Small gold nanospheres & $\downarrow \downarrow \downarrow$ \\
nucleoli & Gold nanoflowers & $\downarrow \downarrow$ \\
& Big gold nanospheres & $\leftrightarrow / \downarrow$ \\
De novo RNA synthesis in & Small gold nanospheres + heat $\downarrow \downarrow \downarrow \downarrow$ \\
nucleoli & shock & \\
& Gold nanoflowers + heat & $\downarrow \downarrow \downarrow \downarrow$ \\
& shock & \\
& Big gold nanospheres + heat & $\downarrow \downarrow \downarrow \downarrow$ \\
\hline
\end{tabular}

The impact of different GNPs on MCF7 cell viability and nucleolar activity is summarized. $\downarrow$ decrease in activity, $\leftrightarrow$ little effect. Note that the outcomes are similar for cell survival (as indicated by mitochondrial metabolic activity) and de novo RNA synthesis in nucleoli

proliferation. The reasons for these differences are not understood; due to their size small nanospheres may have increased access to the cell, thereby enhancing damage and ultimately causing cell death. This interpretation is supported by our results for big gold nanospheres, which had little effect on nuclear and nucleolar parameters or the survival of MCF7 cells.

Surprisingly, when combined with hyperthermia, all GNPs had a profound impact on nucleolar function, and 
this included big gold nanospheres. Several not mutually exclusive explanations are possible for the heat-dependent damage to nucleolar RNA synthesis by large gold nanospheres. First, heat shock increased the association of big gold nanospheres with nuclei. Second, big gold nanospheres have a higher heat capacity as compared to the small gold nanospheres and will therefore emit more heat. Together, this may locally increase damage in the nucleus, where nucleolar functions could be particularly sensitive.

In the absence of hyperthermia, the nucleoli of MCF7 cells were especially vulnerable to small gold nanospheres and gold nanoflowers. However, this is not a common property of human breast cells. Thus, in HuMEC, these GNPs did not cause profound changes in nuclear morphology, nor did they interfere with de novo RNA synthesis. The divergent responses of hsc70 in MCF7 cells and HuMEC further support the idea that hsp70 family members and the stress response are dysregulated in cancer cells [55].

Taken together, our studies link the toxicity of gold nanoparticles to the damage they inflict at the subcellular and molecular levels. Given the importance of chaperones and nucleoli to the growth and proliferation of cancer cells, the ability of GNPs to modulate chaperone and nucleolar biology is of particular interest for nanooncology. Our results emphasize the value of nucleoli as a target for anti-cancer therapy, as the loss of nucleolar activity correlated directly with cell survival (Table 1).

We further demonstrated that breast cancer cell nucleoli are remarkably susceptible to the treatment with GNPs and hyperthermia. This sets the stage to further explore GNPs with other nanomorphologies, such as nanoflowers, in the future because they absorb NIR light and produce heat efficiently [56]. Based on the quantitative differences observed for gold nanospheres and nanoflowers, we propose that the geometry and size of GNPs are critical factors that have to be considered for the design of effective nanotherapeutic strategies that target the nucleus and nucleolus.

Acknowledgments The authors are supported by grants from CIHR (Canadian Institutes of Health Research), NSERC (Natural Sciences and Engineering Council of Canada) and FQRNT (Fonds de Recherche du Québec-Nature et Technologies).

\section{References}

1. Au L, Chen J, Wang LV, Xia Y (2010) Gold nanocages for cancer imaging and therapy. Methods Mol Biol 624:83-99

2. Bickford L, Sun J, Fu K, Lewinski N, Nammalvar V, Chang J, Drezek R (2008) Enhanced multi-spectral imaging of live breast cancer cells using immunotargeted gold nanoshells and two-photon excitation microscopy. Nanotechnology 19:315102

3. Chanda N, Kattumuri V, Shukla R, Zambre A, Katti K, Upendran A, Kulkarni RR, Kan P, Fent GM, Casteel SW, Smith CJ, Boote E, Robertson JD, Cutler C, Lever JR, Katti KV, Kannan R (2010)
Bombesin functionalized gold nanoparticles show in vitro and in vivo cancer receptor specificity. Proc Natl Acad Sci 107:87608765. doi:10.1073/pnas.1002143107

4. Choi J, Yang J, Park J, Kim E, Suh J-S, Huh Y-M, Haam S (2011) Specific near-IR absorption imaging of glioblastomas using integrin-targeting gold nanorods. Adv Funct Mater 21(6):1082-1088. doi:10.1002/adfm.201002253

5. Maltez-da Costa M, de la Escosura-Muniz A, Nogues C, Barrios L, Ibabanez E, Merkoci A (2012) Simple monitoring of cancer cells using nanoparticles. Nano Lett 12(8):4164-4171. doi:10.1021/nl301726g

6. Cheng Y, Samia CA, Meyers JD, Panagopoulos I, Fei B, Burda C (2008) Highly efficient drug delivery with gold nanoparticle vectors for in vivo photodynamic therapy of cancer. J Am Chem Soc 130(32):10643-10647. doi:10.1021/ja801631c

7. Wang T, Zhang X, Pan Y, Miao X, Su Z, Wang C, Li X (2011) Fabrication of doxorubicin functionalized gold nanorod probes for combined cancer imaging and drug delivery. Dalton Trans 40(38):9789-9794

8. Jung Y, Reif R, Zeng Y, Wang RK (2011) Three-dimensional highresolution imaging of gold nanorods uptake in sentinel lymph nodes. Nano Lett 11(7):2938-2943. doi:10.1021/nl2014394

9. Huang Y-F, Sefah K, Bamrungsap S, Chang H-T, Tan W (2008) Selective photothermal therapy for mixed cancer cells using aptamer-conjugated nanorods. Langmuir 24(20):11860-11865. doi: $10.1021 / 1 \mathrm{la} 801969 \mathrm{c}$

10. Jain PK, Huang X, El-Sayed IH, El-Sayed MA (2008) Noble metals on the nanoscale: optical and photothermal properties and some applications in imaging, sensing, biology, and medicine. Acc Chem Res 41(12):1578-1586. doi:10.1021/ar7002804

11. Zhang JZ (2010) Biomedical applications of shape-controlled plasmonic nanostructures: a case study of hollow gold nanospheres for photothermal ablation therapy of cancer. J Phys Chem Lett 1(4):686-695. doi:10.1021/jz900366c

12. von Maltzahn G, Park J-H, Lin KY, Singh N, Schwoppe C, Mesters R, Berdel WE, Ruoslahti E, Sailor MJ, Bhatia SN (2011) Nanoparticles that communicate in vivo to amplify tumour targeting. Nat Mater 10(7):545-552

13. Gobin AM, Watkins EM, Quevedo E, Colvin VL, West JL (2010) Near-infrared-resonant gold/gold sulfide nanoparticles as a photothermal cancer therapeutic agent. Small 6(6):745-752. doi:10.1 002/smll.200901557

14. Kennedy LC, Bickford LR, Lewinski NA, Coughlin AJ, Hu Y, Day ES, West JL, Drezek RA (2011) A new era for cancer treatment: gold-nanoparticle-mediated thermal therapies. Small 7(2):169-183. doi:10.1002/smll.201000134

15. Hutter E, Maysinger D (2011) Gold nanoparticles and quantum dots for bioimaging. Microsc Res Tech 74(7):592-604. doi:10.10 02/jemt.20928

16. Salminen A, Kaarniranta K, Salminen A, Kaarniranta K (2009) SIRT1 regulates the ribosomal DNA locus: epigenetic candles twinkle longevity in the Christmas tree. Biochem Biophys Res Commun 378(1):6-9

17. Chithrani BD, Chan WCW (2007) Elucidating the mechanism of cellular uptake and removal of protein-coated gold nanoparticles of different sizes and shapes. Nano Lett 7(6):1542-1550. doi:10.1021/n1070363y

18. Hutter E, Boridy S, Labrecque S, Lalancette-Hebert M, Kriz J, Winnik FM, Maysinger D (2010) Microglial response to gold nanoparticles. ACS Nano 4(5):2595-2606. doi:10.1021/nn901869f

19. Qiu Y, Liu Y, Wang L, Xu L, Bai R, Ji Y, Wu X, Zhao Y, Li Y, Chen C (2010) Surface chemistry and aspect ratio mediated cellular uptake of Au nanorods. Biomaterials 31(30):7606-7619

20. Albanese A, Tang PS, Chan WCW (2012) The effect of nanoparticle size, shape, and surface chemistry on biological systems. Ann Rev Biomed Eng 14:1-16. doi:10.1146/annurev-bioeng-071811-150124 
21. Boisvert F-M, van Koningsbruggen S, Navascues J, Lamond AI (2007) The multifunctional nucleolus. Nat Rev Mol Cell Biol 8(7):574-585

22. Boulon S, Westman BJ, Hutten S, Boisvert F-M, Lamond AI (2010) The nucleolus under stress. Mol Cell 40(2):216-227

23. Belin S, Beghin A, Solano-Gonzalez E, Bezin L, Brunet-Manquat S, Textoris J, Prats AC, Mertani HC, Dumontet C, Diaz JJ (2009) Dysregulation of ribosome biogenesis and translational capacity is associated with tumor progression of human breast cancer cells. PLoS One 4(9):e7147

24. Derenzini M, Ceccarelli C, Santini D, Taffurelli M, Trere D (2004) The prognostic value of the AgNOR parameter in human breast cancer depends on the $\mathrm{pRb}$ and $\mathrm{p} 53$ status. J Clin Pathol 57(7):755-761

25. Derenzini M, Montanaro L, Trere D (2009) What the nucleolus says to a tumour pathologist. Histopathology 54(6):753-762

26. Maggi LB Jr, Weber JD (2005) Nucleolar adaptation in human cancer. Cancer Invest 23(7):599-608

27. Mello ML, Vidal BC, Russo J, Planding W, Schenck U (2008) Image analysis of the AgNOR response in ras-transformed human breast epithelial cells. Acta Histochem 110(3):210-216

28. Cann DL, Dellaire G (2010) Nucleolus as a biomarker in cancer: past and future. Can J Pathol 21(1):30-34

29. Jamison JM, Gilloteaux J, Perlaky L, Thiry M, Smetana K, Neal D, McGuire K, Summers JL (2010) Nucleolar changes and fibrillarin redistribution following apatone treatment of human bladder carcinoma cells. J Histochem Cytochem 58(7):635-651

30. Jiang MC, Luo SF, Li LT, Lin CC, Du SY, Lin CY, Hsu YW, Liao CF (2007) Synergic CSE1L/CAS, TNFR-1, and p53 apoptotic pathways in combined interferon-gamma/adriamycin-induced apoptosis of Hep G2 hepatoma cells. J Exp Clin Cancer Res 26(1):91-99

31. Kettern N, Dreiseidler M, Tawo R, Hohfeld J (2010) Chaperoneassisted degradation: multiple paths to destruction. Biol Chem 391(5):481-489

32. Massey AJ, Williamson DS, Browne H, Murray JB, Dokurno P, Shaw T, Macias AT, Daniels Z, Geoffroy S, Dopson M, Lavan P, Matassova N, Francis GL, Graham CJ, Parsons R, Wang Y, Padfield A, Comer M, Drysdale MJ, Wood M (2010) A novel, small molecule inhibitor of Hsc70/Hsp70 potentiates Hsp90 inhibitor induced apoptosis in HCT116 colon carcinoma cells. Cancer Chemother Pharmacol 66(3):535-545

33. Behrens P, Brinkmann U, Wellmann A (2003) CSE1L/CAS: its role in proliferation and apoptosis. Apoptosis 8(1):39-44

34. Tanaka T, Ohkubo S, Tatsuno I, Prives C, Tanaka T, Ohkubo S, Tatsuno I, Prives C (2007) HCAS/CSE1L associates with chromatin and regulates expression of select p53 target genes. Cell 130(4):638-650

35. Sharp A, Cutress RI, Johnson PW, Packham G, Townsend PA, Sharp A, Cutress RI, Johnson PWM, Packham G, Townsend PA (2009) Short peptides derived from the BAG-1 C-terminus inhibit the interaction between BAG-1 and HSC70 and decrease breast cancer cell growth. FEBS Lett 583(21):3405-3411

36. Tai C-J, Shen S-C, Lee W-R, Liao C-F, Deng W-P, Chiou H-Y, Hsieh C-I, Tung J-N, Chen C-S, Chiou J-F, Li L-T, Lin C-Y, Hsu C-H, Jiang M-C (2010) Increased cellular apoptosis susceptibility (CSE1L/CAS) protein expression promotes protrusion extension and enhances migration of MCF-7 breast cancer cells. Exp Cell Res 316(17):2969-2981

37. Burke B, Stewart CL (2013) The nuclear lamins: flexibility in function. Nat Rev Mol Cell Biol 14(1):13-24

38. Strasser C, Grote P, Schauble K, Ganz M, Ferrando-May E (2012) Regulation of nuclear envelope permeability in cell death and survival. Nucleus 3(6):540-551

39. Wang J, Li YF, Huang CZ, Wu T (2008) Rapid and selective detection of cysteine based on its induced aggregates of cetyltrimethylammonium bromide capped gold nanoparticles. Anal Chim Acta 626(1):37-43

40. Yuanyuan J, Xue-Jun W, Qi L, Jingjian L, Dongsheng X (2011) Facile synthesis of gold nanoflowers with high surface-enhanced Raman scattering activity. Nanotechnology 22(38):385601

41. UTHSCSA (2012) UTHSCSA Image Tool version 3.0. vol 2012. http://compdent.uthscsa.edu/dig/download.html

42. Banski P, Mahboubi H, Kodiha M, Shrivastava S, Kanagaratham C, Stochaj U (2010) Nucleolar targeting of the chaperone hsc70 is regulated by stress, cell signaling, and a composite targeting signal which is controlled by autoinhibition. J Biol Chem 285(28):21858-21867

43. Patre M, Tabbert A, Hermann D, Walczak H, Rackwitz H-R, Cordes VC, Ferrando-May E (2005) Caspases target only two architectural components within the core structure of the nuclear pore complex. J Biol Chem 281:1296-1304. doi:10.1074/jbc. M511717200

44. Kodiha M, Ho-Wo-Cheong D, Stochaj U (2011) Pharmacological AMP-kinase activators have compartment-specific effects on cell physiology. Am J Physiol Cell Physiol 301(6):C1307-C1315. doi :10.1152/ajpcell.00309.2011

45. Kodiha M, Banski P, Stochaj U (2011) Computer-based fluorescence quantification: a novel approach to study nucleolar biology. BMC Cell Biol 12(1):25

46. Kodiha M, Brown CM, Stochaj U (2008) Analysis of signaling events by combining high-throughput screening technology with computer-based image analysis. Sci Signal 1(37):pl2

47. Su H, Kodiha M, Lee S, Stochaj U (2013) Identification of novel markers that demarcate the nucleolus during severe stress and chemotherapeutic treatment. PLoS One 8(11):e80237. doi:10.1371/journal.pone.0080237

48. Schmidt B, Loeschner K, Hadrup N, Mortensen A, Sloth JJ, Koch CB, Larsen EH (2011) Quantitative characterization of gold nanoparticles by field-flow fractionation coupled online with light scattering detection and inductively coupled plasma mass spectrometry. Anal Chem 83(7):2461-2468

49. Calzolai L, Gilliland D, Garcia CP, Rossi F (2011) Separation and characterization of gold nanoparticle mixtures by flow-fieldflow fractionation. J Chromatogr A 1218(27):4234-4239

50. Wojciechowski J, Horky M, Gueorguieva M, Wesierska-Gadek J (2003) Rapid onset of nucleolar disintegration preceding cell cycle arrest in roscovitine-induced apoptosis of human MCF-7 breast cancer cells. Int J Cancer 106(4):486-495

51. Dickson KK, Diego AR, Carl AB (2010) Gold hybrid nanoparticles for targeted phototherapy and cancer imaging. Nanotechnology 21(10): 105105

52. Kodiha M, Banski P, Ho-Wo-Cheong D, Stochaj U (2008) Dissection of the molecular mechanisms that control the nuclear accumulation of transport factors importin-alpha and CAS in stressed cells. Cell Mol Life Sci 65(11):1756-1767

53. Kodiha M, Chu A, Lazrak O, Stochaj U (2005) Stress inhibits nucleocytoplasmic shuttling of heat shock protein hsc70. Am J Physiol Cell Physiol 289(4):C1034-C1041

54. Pelham HR (1984) Hsp70 accelerates the recovery of nucleolar morphology after heat shock. EMBO J 3(13):3095-3100

55. Evans CG, Chang L, Gestwicki JE (2010) Heat shock protein 70 (Hsp70) as an emerging drug target. J Med Chem 53(12):45854602. doi:10.1021/jm100054f

56. Van de Broek B, Devoogdt N, D'Hollander A, Gijs H-L, Jans K, Lagae L, Muyldermans S, Maes G, Borghs G (2011) Specific cell targeting with nanobody conjugated branched gold nanoparticles for photothermal therapy. ACS Nano 5(6):4319-4328. doi:10.1021/nn1023363 